\title{
Abundance of Phase 1 and 2 Drug-Metabolizing Enzymes in Alcoholic and Hepatitis C Cirrhotic Livers: A Quantitative Targeted Proteomics Study ${ }^{\mathbb{A}}$
}

Bhagwat Prasad, Deepak Kumar Bhatt, Katherine Johnson, Revathi Chapa, Xiaoyan Chu, Laurent Salphati, Guangqing Xiao, Caroline Lee, Cornelis E. C. A. Hop, Anita Mathias, Yurong Lai, Mingxiang Liao, William G. Humphreys, Sean C. Kumer, and Jashvant D. Unadkat

University of Washington, Seattle, Washington (B.P., D.K.B., K.J., R.C., J.D.U.); Merck Sharp \& Dohme Corporation, Kenilworth, New Jersey (X.C.); Gilead Sciences, Inc., Foster City, California (A.S.R., A.M.); Genentech, South San Francisco, California (L.S., C.E.C.A.H.); Biogen, Cambridge, Massachusetts (G.X.); Ardea Biosciences, Inc., San Diego, California (C.L.); Bristol-Myers Squibb Company, Princeton, New Jersey (Y.L., W.H.); Takeda Pharmaceuticals International Co., Cambridge, Massachusetts (M.L.); and University of Kansas Medical Center, Kansas City, Kansas (S.C.K.)

Received January 16, 2018; accepted April 13, 2018

\section{ABSTRACT}

To predict the impact of liver cirrhosis on hepatic drug clearance using physiologically based pharmacokinetic (PBPK) modeling, we compared the protein abundance of various phase 1 and phase 2 drug-metabolizing enzymes (DMEs) in $\mathbf{S 9}$ fractions of alcoholic ( $n=27)$ or hepatitis $\mathrm{C}(\mathrm{HCV}, n=30)$ cirrhotic versus noncirrhotic (control) livers $(n=25)$. The S9 total protein content was significantly lower in alcoholic or HCV cirrhotic versus control livers (i.e., $38.3 \pm 8.3,32.3 \pm 12.8$, vs. $51.1 \pm 20.7 \mathrm{mg} / \mathrm{g}$ liver, respectively). In general, alcoholic cirrhosis was associated with a larger decrease in the DME abundance than HCV cirrhosis; however, only the abundance of UGT1A4, alcohol dehydrogenase (ADH)1A, and ADH1B was significantly lower in alcoholic versus HCV cirrhotic livers. When normalized to per gram of tissue, the abundance of nine DMEs (UGT1A6, UGT1A4, CYP3A4, UGT2B7, CYP1A2, ADH1A, ADH1B, aldehyde oxidase (AOX)1, and carboxylesterase (CES)1) in alcoholic cirrhosis and five DMEs (UGT1A6, UGT1A4, CYP3A4, UGT2B7, and CYP1A2) in HCV cirrhosis was $<25 \%$ of that in control livers. The abundance of most DMEs in cirrhotic livers was $25 \%$ to $50 \%$ of control livers. CES2 abundance was not affected by cirrhosis. Integration of UGT2B7 abundance in cirrhotic livers into the liver cirrhosis (Child Pugh C) model of Simcyp improved the prediction of zidovudine and morphine PK in subjects with Child Pugh $\mathrm{C}$ liver cirrhosis. These data demonstrate that protein abundance data, combined with PBPK modeling and simulation, can be a powerful tool to predict drug disposition in special populations.

\section{Introduction}

Liver cirrhosis affects half a million adults in the United States and is the fifth leading cause of death in the 45- to 54-year age group (Scaglione et al., 2015). The predominant causes of liver cirrhosis are viral hepatitis [especially hepatitis $\mathrm{C}(\mathrm{HCV})$ ], sustained excessive alcohol consumption, and diabetes. Therefore, the prevalence of liver cirrhosis is expected to increase owing to the aging hepatitis $\mathrm{C}$ cohort and an upsurge in alcoholic fatty liver disease and diabetes (Davis et al., 2010). Liver cirrhosis is characterized by irreversible scarring of liver tissue with progressive loss of functional hepatocytes from obstruction of hepatic blood flow (Bataller and Brenner, 2005).

The study was supported by UWRAPT funded by a consortium of pharmaceutical companies (Genentech, Merck, Gilead, BMS, Ardea Biosciences, Takeda and Biogen), and Eunice Kennedy Shriver National Institute of Child Health and Human Development [Grant R01HD081299].

https://doi.org/10.1124/dmd.118.080523.

S This article has supplemental material available at dmd.aspetjournals.org.
The pharmacokinetics (PK) of numerous drugs is altered in patients with liver cirrhosis, especially when the drugs are cleared predominately by hepatic metabolism. These changes are known to be caused by dysregulation of protein expression of drug-metabolizing enzymes (DMEs) and transporters, altered hepatic blood flow, and decreased plasma protein binding (Johnson et al., 2010; Wang et al., 2016; Rasool et al., 2017). Therefore, the Food and Drug Administration has recommended that clinical studies be conducted in patients with various degrees of hepatic impairment for all narrow therapeutic index drugs predominately cleared by the liver, as well as wide therapeutic index drugs if more than $20 \%$ of the drug is cleared by the liver (http://www. fda.gov/downloads/drugs/guidancecomplianceregulatoryinformation/ guidances/ucm072123); however, studying the PK of all such drugs in patients with hepatic impairment is logistically challenging. Therefore, alternate approaches, such as physiologically based PK (PBPK) models, are proving useful in predicting drug dose adjustments in patients with hepatic impairment. In at least four instances, new drug sponsors have applied PBPK modeling to predict the effect of hepatic impairment during regulatory submission (Jamei, 2016). These PBPK models

ABBREVIATIONS: ADH, alcohol dehydrogenase; ALDH, aldehyde dehydrogenase; AOX, aldehyde oxidase; AUC, area under the curve; CES, carboxylesterase; DMEs, drug-metabolizing enzymes; EPHX, epoxide hydrolase; $F_{\mathrm{a}}$, fraction absorbed, FMO, flavin monooxygenase; $f_{\mathrm{u}}$, fraction unbound; LC-MS/MS, liquid chromatography-tandem mass spectrometry; OCT1, organic cation transporter; P450, cytochrome P450; PBPK, physiologically based pharmacokinetic; $V_{\text {ss }}$, steady-state volume of distribution. 
incorporate change in the in vivo hepatic enzyme activity by administering selective probe substrates to patients with liver disease or by measuring their enzyme activity or protein abundance (by Western blotting) in vitro (Johnson et al., 2010); however, such studies are not comprehensive as they are limited to enzymes that have selective probes or antibodies (Woodhouse et al., 1985; Johnson et al., 2010). Therefore, the aims of this study were 1) to determine the effect of HCV and alcoholic cirrhosis on protein abundance of multiple hepatic phase 1 and phase 2 drug-metabolizing enzymes (DMEs) using quantitative targeted proteomics and 2) to determine whether the protein abundance data in cirrhotic versus noncirrhotic (control) livers can improve prediction of the disposition of drugs in cirrhotic subjects that are metabolized (e.g., zidovudine) or metabolized and transported (e.g., morphine). The results of this study complement our previous study on the effect of liver cirrhosis on protein abundance of hepatic drug transporters (Wang et al., 2016).

\section{Materials and Methods}

\section{Materials}

Synthetic light (with amino acid analysis) and heavy labeled peptides (Supplemental Table 1S) were purchased from New England Peptides (Boston, MA) and Thermo Fisher Scientific (Rockford, IL), respectively. Chloroform, ethyl ether, Optima MS-grade acetonitrile, methanol, and formic acid were purchased from Fischer Scientific (Fair Lawn, NJ). Ammonium bicarbonate (98\% pure) and sodium deoxycholate (98\% pure) were procured from Thermo Fisher Scientific and MP Biomedicals (Santa Ana, CA), respectively. Purified CES1 protein standard was procured from Abcam, Inc. (Cambridge, MA) and purified CES2, ADH1A, ADH1B, ADH1C, and aldehyde dehydrogenase (ALDH)1A1 proteins were purchased from Abnova (Walnut, CA), respectively.

\section{Human S9 Fraction Isolation}

S9 fractions were isolated as described already (Shi et al., 2016) from control $(n=25), \mathrm{HCV}$ cirrhotic $(n=30)$, and alcoholic cirrhotic $(n=27)$ livers obtained from multiple sources (Supplemental Table 1S). The characteristics of these livers have been described previously (Wang et al., 2016). The cirrhotic livers were obtained from patients with end-stage liver disease and therefore were assumed for PBPK modeling to represent patients with Child Pugh score C. About $100 \mathrm{mg}$ of human liver tissue was transferred to a $15-\mathrm{ml}$ centrifuge tube on ice containing $3.5 \mathrm{ml}$ of chilled homogenization buffer $(50 \mathrm{mM}$ phosphate buffer, $0.25 \mathrm{M}$ sucrose, $1 \mathrm{mM}$ EDTA). The tissue was homogenized and centrifuged at $9000 \mathrm{~g}$ at $4^{\circ} \mathrm{C}$. The supernatant (i.e., S9 fraction) was collected, and total protein concentration was determined using bicinchoninic acid (BCA) protein assay using the Pierce BCA protein assay kit (Thermo Fisher Scientific) per manufacturer's protocol. Each S9 fraction was diluted to $2 \mathrm{mg} / \mathrm{ml}$ total protein and stored at $-80^{\circ} \mathrm{C}$.

\section{Sample Preparation}

CESs, ADHs, and ALDH1A1 protein abundance was quantified using purified protein standards. The remaining proteins were quantified using the peptide standards except aldehyde oxidase 1 (AOX1), flavin mono-oxygenase 3 (FMO3), and epoxide hydrolases (EPHX1 and EPHX2), for which only relative quantification was conducted. Irrespective of the type of the calibrator used, stable-labeled peptides were used as internal standards for quantification of all proteins. S9 fraction samples were digested by trypsin (in triplicate) as described previously (Boberg et al., 2017). The digested samples were processed and analyzed by liquid chromatography-tandem mass spectrometry (LC-MS/MS) on three different days to account for technical variability (Bhatt and Prasad, 2017). The calibrators for quantifying purified proteins (CESs, ADHs, and ALDH1A1) were prepared by diluting them with $50 \mathrm{mM}$ phosphate buffer ( $\mathrm{pH}$ 7.4) to generate working calibrator concentrations ranging from 0.5 to $5000 \mathrm{pmol} / \mathrm{ml}$ (number of calibrators was 6-10). Ten microliters of the working calibrators were added to $70 \mu \mathrm{l}$ of phosphate buffer. Subsequently, $80 \mu \mathrm{l}$ of the calibrator or S9 sample $(2 \mathrm{mg} / \mathrm{ml})$ were combined with $10 \mu \mathrm{l}$ of dithiothreitol $(250 \mathrm{mM}), 40 \mu \mathrm{l}$ ammonium bicarbonate buffer (100 mM, pH 7.8), and $20 \mu \mathrm{l}$ deoxycholic acid (10\%). Ten microliters of human serum albumin $(10 \mathrm{mg} / \mathrm{ml})$ was added, and the mix was incubated at $95^{\circ} \mathrm{C}$ for 10 minutes with gentle shaking at $300 \mathrm{rpm}$. Samples were cooled to room temperature for 10 minutes before adding $20 \mu \mathrm{l}$ of iodoacetamide $(500 \mathrm{mM})$ for incubation in the dark for 30 minutes at room temperature. Then, $500 \mu \mathrm{l}$ of ice-cold methanol, $100 \mu \mathrm{l}$ of ice-cold chloroform, and $400 \mu \mathrm{l}$ of cold water were added to each sample, vortex-mixed, and subjected to centrifugation at $12,000 \mathrm{~g}\left(4^{\circ} \mathrm{C}\right)$ for 5 minutes. The upper and lower layers were removed using vacuum suction, and the pellets were dried at room temperature for 10 minutes. The pellets were subsequently washed with $500 \mu \mathrm{l}$ of ice-cold methanol and subjected to centrifugation at $8000 \mathrm{~g}\left(4^{\circ} \mathrm{C}\right)$ for 5 minutes, after which the supernatant was removed. Then, the pellets were dried at room temperature for 30 minutes and resuspended in $60 \mu \mathrm{l}$ of ammonium bicarbonate buffer $(50 \mathrm{mM}, \mathrm{pH} 7.8)$. For digestion, $20 \mu \mathrm{l}$ of trypsin $(0.16$ $\mu \mathrm{g} / \mu \mathrm{l})$ was added to the mix $\left(37^{\circ} \mathrm{C}, 16\right.$ hours, gentle shaking at $\left.300 \mathrm{rpm}\right)$. The trypsin digestion was quenched by placing samples on dry ice. Then, $20 \mu \mathrm{l}$ of heavy peptide internal standard cocktail (dissolved in acetonitrile:water, 80:20 $(\mathrm{v} / \mathrm{v})$ with $0.5 \%$ formic acid) were added. To the calibrators, $10 \mu \mathrm{l}$ of acetonitrile:water $80: 20(\mathrm{v} / \mathrm{v})$ with $0.5 \%$ formic acid or light peptide calibrator working solutions ( $n=8$, final concentrations, $0.1-1000 \mathrm{pmol} / \mathrm{ml})$ were added. After mixing and centrifuging at $4000 \mathrm{~g}\left(4^{\circ} \mathrm{C}\right)$ for 5 minutes, samples were transferred to LC-MS/MS autosampler vials.

\section{LC-MS/MS Analyses}

The LC-MS/MS system consisted of an Acquity UPLC (Waters Technologies, Milford, MA) coupled to a Sciex Triple Quad 6500 system (Framingham, MA). The surrogate peptides were selected (Supplemental Table 2S) using an optimized protocol (Drozdzik et al., 2014) for the quantification of protein abundance. Peptide separation was achieved on an Acquity UPLC column (HSS T3 $1.8 \mu \mathrm{m}$.

TABLE 1

Input parameters used for zidovudine physiologically based pharmacokinetic (PBPK) simulations

\begin{tabular}{|c|c|c|c|}
\hline PBPK Parameter & Control & Cirrhotic & Methods/Reference \\
\hline Molecular mass $(\mathrm{g} / \mathrm{mol})$ & & 267.2 & Simcyp library \\
\hline $\log P$ & & 0.05 & Simcyp library \\
\hline Acid dissociation constant (pKa) & & 9.7 & Simcyp library \\
\hline Blood-to-plasma ratio & & 0.91 & Simcyp library \\
\hline Unbound fraction $\left(F_{\mathrm{u}}\right)$ & & 0.8 & Simcyp library \\
\hline Fraction absorbed $\left(F_{\mathrm{a}}\right)$ & & 0.83 & $\begin{array}{l}\text { Predicted by advanced dissolution, absorption, } \\
\text { and metabolism model }\end{array}$ \\
\hline$k_{\mathrm{a}}\left(\mathrm{h}^{-1}\right)$ & & 4.05 & Zhang and Unadkat (2017a) \\
\hline Distribution model & \multicolumn{3}{|c|}{ Minimal PBPK model } \\
\hline Steady-state volume of distribution $\left(V_{\mathrm{ss}}\right.$, liters $/ \mathrm{kg}$ ) & & 1.1 & Zhang and Unadkat (2017a) \\
\hline Renal clearance (liters/h) & & 13.2 & Singlas et al. (1989), Taburet et al. (1990) \\
\hline CLint,UGT2B7 ( $\mu 1 /$ min per milligram) & 29.5 & 6.5 (78\% decrease) & $\begin{array}{l}\text { Estimated from literature (Singlas et al., 1989; } \\
\text { Taburet et al., 1990) and based on protein } \\
\text { abundance data }\end{array}$ \\
\hline Additional clearance $\mathrm{CL}_{\text {int, }} \mathrm{P} 450 \mathrm{~s}$, others $($ liters $/ \mathrm{h}$ ) & 3.07 & $1.01(67 \%$ decrease $)$ & $\begin{array}{l}\text { Estimated from literature (Stagg et al., 1992) } \\
\text { and based on protein abundance data }\end{array}$ \\
\hline
\end{tabular}


TABLE 2

Input parameters used for morphine physiologically based pharmacokinetic (PBPK) simulations

\begin{tabular}{|c|c|c|}
\hline PBPK Parameter & Control Cirrhotic & Method/Reference \\
\hline Molecular mass $(\mathrm{g} / \mathrm{mol})$ & 285.34 & Simcyp library \\
\hline $\log \mathrm{P}$ & 0.77 & Emoto et al. (2017) \\
\hline Acid dissociation constant (pKa) & 7.9 & Emoto et al. (2017) \\
\hline pKa2 & \multirow{2}{*}{$\begin{array}{l}9.6 \\
1.08\end{array}$} & Emoto et al. (2017) \\
\hline Blood-to-plasma ratio & & Emoto et al. (2017) \\
\hline Unbound fraction $\left(F_{\mathrm{u}}\right)$ & 0.62 & Emoto et al. (2017) \\
\hline Full PBPK model & & \\
\hline$V_{\mathrm{ss}}($ liters $/ \mathrm{kg})$ & 3.6 & Method 2 (Rodgers et al., 2005) \\
\hline \multicolumn{3}{|l|}{ Enzyme kinetics } \\
\hline \multicolumn{3}{|l|}{ (HLM) } \\
\hline \multicolumn{3}{|l|}{ UGT2B7/M3G } \\
\hline$K_{\mathrm{m}}(\mu \mathrm{mol} /$ liter) of human liver microsomes $(\mathrm{M} 3 \mathrm{G})$ & 115.8 & Reported (Emoto et al., 2017) \\
\hline $\begin{array}{l}V_{\max }(\mathrm{pmol} / \mathrm{min} \text { per milligram of microsomal protein) }(\mathrm{M} 3 \mathrm{G}) \\
\text { UGT2B7/M6G }\end{array}$ & $9250 \quad 2035^{\mathrm{a}}$ & Reported (Emoto et al., 2017) \\
\hline Km $(\mu \mathrm{mol} /$ liter $)$ HLM $(\mathrm{M} 6 \mathrm{G})$ & 115.8 & Emoto et al. (2017) \\
\hline$V \max (\mathrm{pmol} / \mathrm{min}$ per milligram microsomal protein) $(\mathrm{M} 6 \mathrm{G})$ & $1917 \quad 421.7^{\mathrm{a}}$ & Emoto et al. (2017) \\
\hline Renal Cl (liters/h) & \multirow[t]{2}{*}{8} & Emoto et al. (2017) \\
\hline Permeability limited liver model & & \\
\hline Transporter kinetics & & \\
\hline $\mathrm{OCT} 1(K \mathrm{~m}) \mu \mathrm{M}$ & 3.4 & Emoto et al. (2017) \\
\hline OCT1 Jmax & $26.4^{\mathrm{a}}$ & Emoto et al. (2017) \\
\hline OCT1 (REF) & 5.1 & Emoto et al. (2017) \\
\hline
\end{tabular}

M3G and M6G are morphine 3- and morphine-6 glucuronide; REF, relative expression factor.

${ }^{a} J_{\max }$ and $V_{\max }$ values were respectively adjusted based on the change in OCT1 and UGT2B7 protein abundance in cirrhotic versus control liver reported previously by us (Wang et al., 2016) or here.

$2.1 \times 100 \mathrm{~mm}$; Waters). Mobile phase A and B consisted of water with formic acid $0.1 \%(\mathrm{v} / \mathrm{v})$ and acetonitrile with formic acid $0.1 \%(\mathrm{v} / \mathrm{v})$, respectively. The injection volume was $5 \mu \mathrm{l}(\sim 10 \mu \mathrm{g}$ of total protein). Peptides were eluted under gradient conditions at a flow rate of $0.3 \mathrm{ml} / \mathrm{min}$. The parent-to-product ion transitions for the analyte peptides and their respective heavy peptides were monitored (multiple reaction monitoring, MRM) using optimized LC-MS/MS parameters (Supplemental Table 2S) in electrospray ionization-positive-ionization mode. Peak integration and quantification were performed using the Analyst software (version 1.6, Mass Spectrometry Toolkit v3.3; Boston, MA).

\section{Data Analysis}

As justified in our previous publication (Prasad et al., 2014), if the DME abundance values were quantified by two peptides and resulted in different values, the higher value was used. The mean of triplicate determination was used for final data analysis. To compare hepatic protein abundance between the three groups (control, alcoholic, and HCV cirrhotic), the Kruskal-Wallis test followed by Dunn's multiple comparison test was used. $P<0.05$ was considered statistically significant.
PBPK Model Development and Verification of Zidovudine and Morphine PK in Control and Cirrhotic (Child Pugh C) Subjects

PBPK models describing zidovudine (200 mg, oral dose) and morphine (4 mg, i.v. dose) PK were developed using population-based Simcyp simulator (Version 15; Sheffield, UK) as follows:

PBPK Model Development for Control Subjects. For zidovudine, a minimal PBPK model was constructed and consisted of a liver compartment and a single adjusting compartment connected to a systemic compartment (Table 1). The advanced dissolution, absorption, and metabolism model was used for drug absorption. Physicochemical and binding parameters [e.g., molecular weight, lipophilicity $(\log \mathrm{P})$, acid dissociation constant $(\mathrm{pKa})$, bloodto-plasma ratio, and fraction unbound in plasma $\left.\left(f_{\mathrm{u}}\right)\right]$ were obtained from the Simcyp library. The fraction of drug absorbed $\left(F_{\mathrm{a}}\right)$ was predicted using the drug's $\log \mathrm{P}$ and polar surface area. Reported values of absorption rate constant $\left(K_{\mathrm{a}}\right)$ and steady-state volume of distribution $\left(V_{\mathrm{ss}}\right)$ were used (Zhang and Unadkat, 2017b). UGT2B7-mediated zidovudine clearance was estimated by Simcyp retrograde enzyme kinetics model considering $\mathrm{Fa}$, oral $\left(\mathrm{Cl}_{\mathrm{po}}\right)$, renal $\left(\mathrm{Cl}_{\mathrm{r}}\right)$, and additional (non-UGT2B7) clearance data from control subjects (Singlas et al., 1989; Taburet et al., 1990; Stagg et al., 1992). A similar approach was used to predict morphine
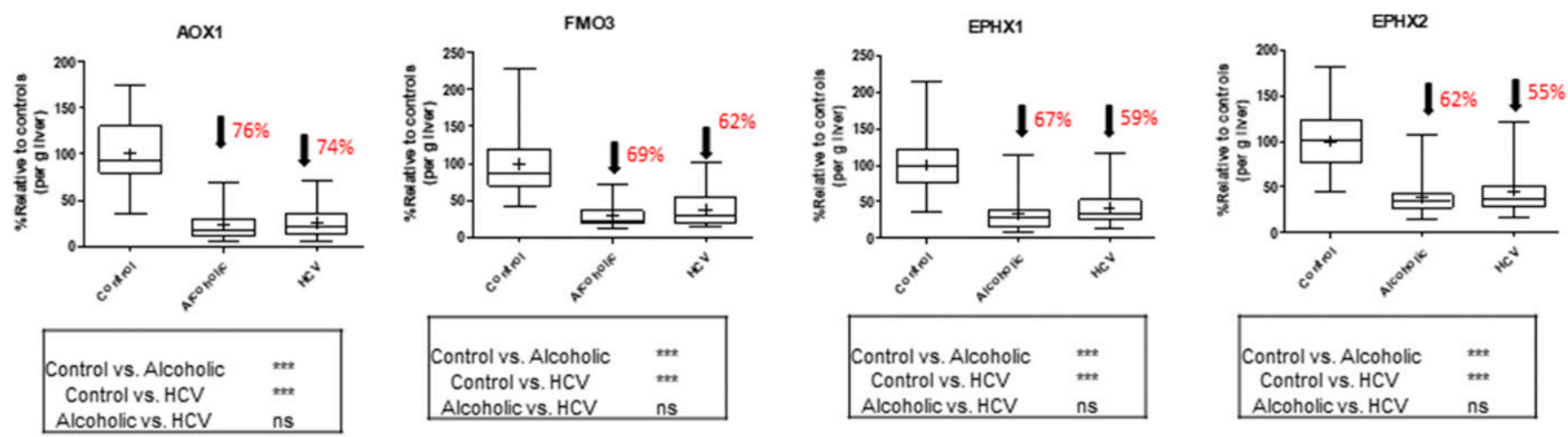

Fig. 1. Total protein content in S9 fractions of control or cirrhotic livers. Total protein content (per gram of liver) in S9 fractions isolated from control, alcoholic, and HCV cirrhotic liver tissues was significantly lower in both alcoholic and HCV cirrhosis livers versus control livers, Data shown are mean \pm S.D. $* P<0.05 ; * * P<0.0001$, respectively, using the Kruskal-Wallis test followed by Dunn's multiple comparison test. 
A
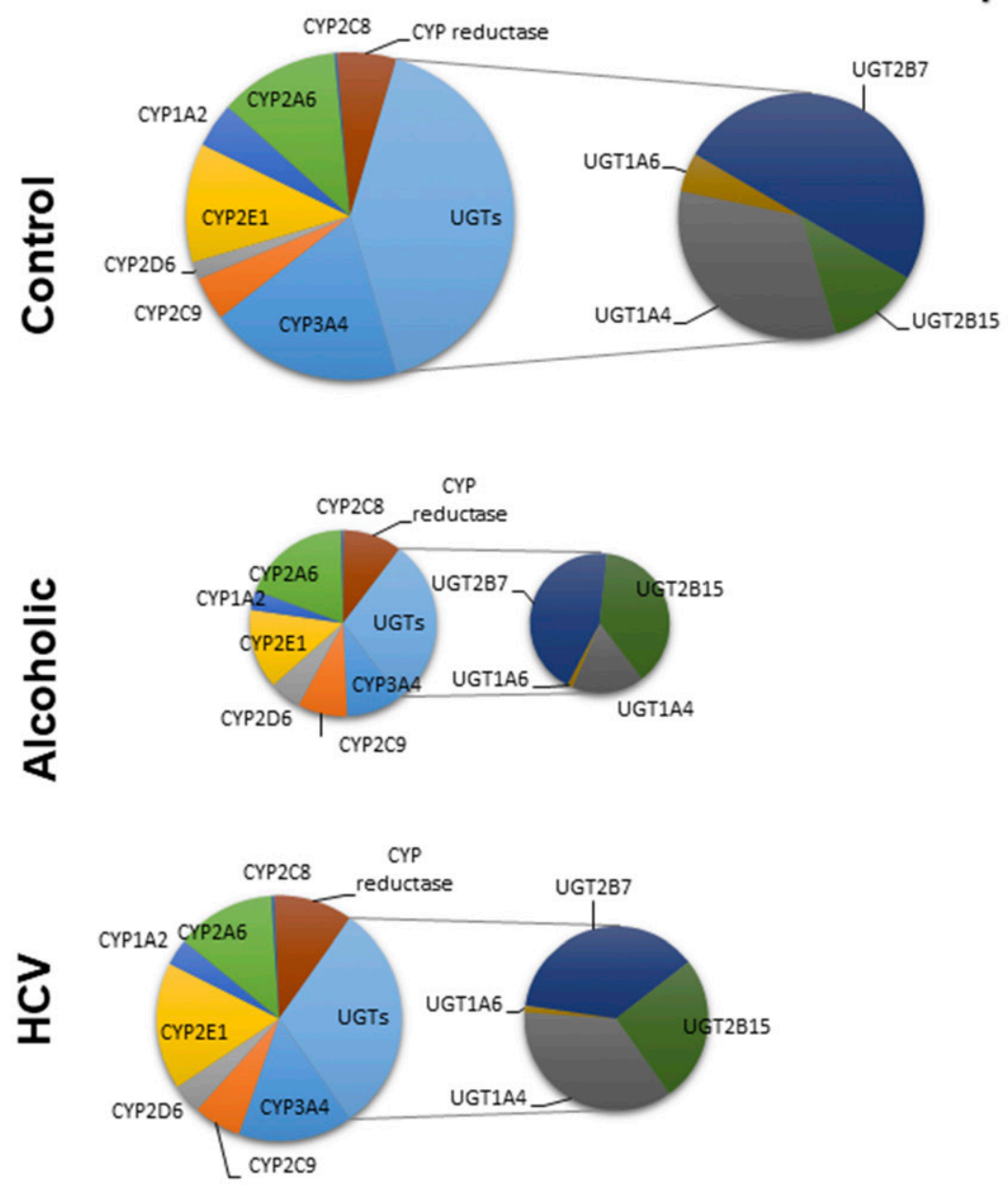

Cytosolic and ER luminal DMEs

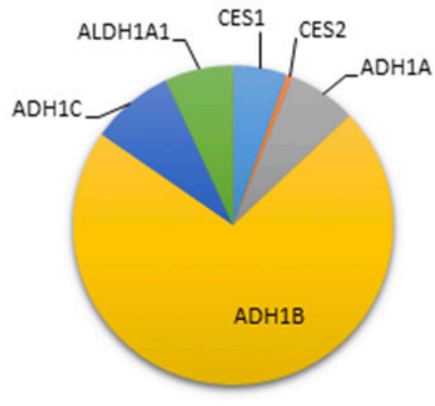

$100 \%$

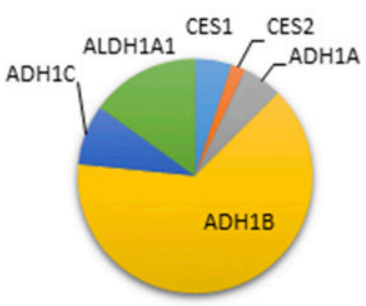

$26 \%$

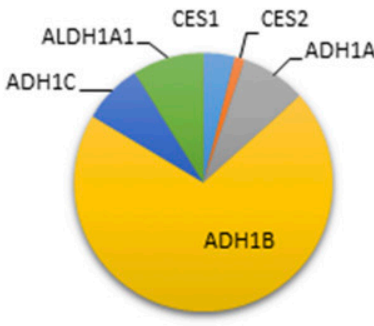

$49 \%$

B
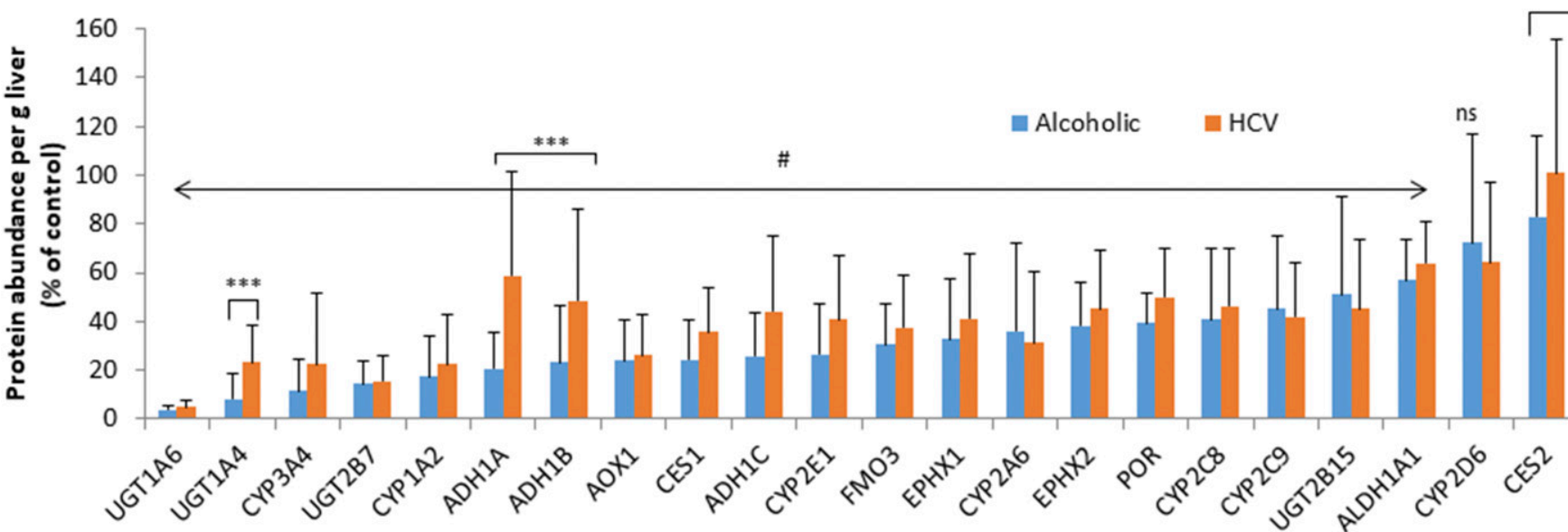

Fig. 2. Relative hepatic DME protein abundance in S9 fractions of control or cirrhotic livers. (A) Relative abundance of membrane-associated or microsomal (left) and soluble (cytosolic or luminal; right) DMEs in control (top), alcoholic (middle) or HCV (bottom) cirrhotic livers. Pie charts represent the abundance of each protein as a percent of the respective total. The percent values listed on the right represent the abundance of all proteins relative to that in control livers (designated as $100 \%$ ). (B) DME abundance in alcoholic or HCV cirrhotic livers is arranged in the order of magnitude of diseased vs. control livers (per gram liver tissue); ns, nonsignificant (vs. control); ${ }^{*} P<0.05$ (vs. control); $* * * P<0.001$. Data shown are mean \pm S.D. The abundance of all DMEs, except CYP2D6 and CES2, was significantly lower in alcoholic or HCV cirrhotic livers vs. control livers. Except for UGT1A4, ADH1A, and ADH1B, the abundance of the DMEs was not significantly different between alcoholic and HCV livers. 
PK (Table 2) except that the full PBPK model was used because, other than UGT2B7, organic cation transporter (OCT1) is also involved in the disposition of morphine (Emoto et al., 2017). Previously developed PBPK model including the reported enzyme/transport kinetics data were used (Emoto et al., 2017). $V_{\mathrm{ss}}$ of morphine was determined by the Rodgers and Rowland method (Rodgers et al., 2005). For each drug, the simulation trial consisted of 100 virtual simulations (10 trials $\times 10$ subjects). This model was evaluated by visual predictive check and by comparison of the observed and predicted values of zidovudine (Singlas et al., 1989; Taburet et al., 1990) and morphine PK (Hasselstrom et al., 1990) parameters. The model was considered accurate if the observed plasma concentrations were within the $90 \%$ prediction interval (5th-95th percentile range) of the virtual population and if the predicted/observed ratio for the mean PK parameters [plasma $C_{\max }$ and area under the curve (AUC)] were within the 0.5 - to 2 -fold range.

PBPK Predictions in Cirrhotic Subjects. Once the control models for zidovudine and morphine were verified, we predicted (using eq. 1) the cirrhosis-dependent decrease in clearance (CL) of zidovudine or morphine via UGT2B7-mediated metabolism or OCT1-mediated hepatic uptake (morphine only) by integrating the protein abundance data (picomoles per milligram of S9 protein) obtained here and previously reported by us (Wang et al., 2016) into the existing Simcyp liver cirrhosis (Child Pugh score C) model. That is, the observed decrease in UGT2B 7 and OCT1 protein abundance (78\% and 9\%, respectively) in the cirrhosis versus the control subjects was used for PBPK modeling and simulation. We did not use the abundance values of these proteins scaled to gram of liver tissue, because Simcyp cirrhosis model already incorporates the decrease in functional liver volume (i.e., milligrams of S9 fraction/membrane protein per gram of liver) resulting from cirrhosis. This cirrhosis Simcyp model also incorporates the effect of portacaval shunting by modifying the "well-stirred" model to consider the fraction of mesenteric blood flow passing through the functioning liver (fMBF) (Johnson et al., 2010). To assess the usefulness of the proteomics data, zidovudine and morphine PK were predicted using the existing Simcyp cirrhosis model without incorporating changes in liver abundance of UGT2B7 and OCT1 owing to cirrhosis:

$$
\begin{gathered}
C L_{U G T 2 B 7 \text { or OCT1 (cirrhotic) }}=C L_{U G T 2 B 7 \text { or OCT1 }}(\text { control }) \\
\times \frac{U G T 2 B 7 \text { or OCT } 1 \text { abundance }}{(\text { cirrhotic })} \\
U G T 2 B 7 \text { or OCT } 1 \text { abundance }{ }_{(\text {control })}
\end{gathered}
$$

Similar to control subject models, the predicted mean plasma concentration-time profile of each drug in cirrhotic patients was compared with the observed profile (Singlas et al., 1989; Hasselstrom et al., 1990; Taburet et al., 1990). The model evaluation criteria were as described under control subjects.

\section{Results}

The total protein yield per gram of tissue in S9 fractions was significantly lower in alcoholic or HCV cirrhotic versus control livers (Fig. 1). Based on surrogate peptide quantification, the rank order of abundance of microsomal cytochrome P450 (P450s), UGTs, and soluble (cytosolic or endoplasmic reticulum luminal) enzymes in S9 fractions (per gram of liver) in control livers was CYP3A4 $>$ CYP2A6 $>$ CYP2E1 $>$ CYP1A2 $>$ CYP2C9 $>$ CYP2D6 $>$ CYP2C8; UGT2B7 > UGT1A4 > UGT2B15> UGT1A6; and ADH1B $>$ ADH1C $>$ $\mathrm{ALDH} 1 \mathrm{~A} 1>\mathrm{ADH} 1 \mathrm{~A}>\mathrm{CES} 1>\mathrm{CES} 2$, respectively (Fig. 2A and, Tables 3 and 4). Overall, total abundance of the quantified proteins in alcoholic and HCV cirrhotic livers was $26 \%$ and $49 \%$ of that in control livers (Fig. 2A). Alcoholic or HCV cirrhosis resulted in a similar decrease $(>50 \%$ vs. control) in hepatic abundance of CYP3A4, CYP1A2, CYP2E1, CYP2A6, cytochrome P450 reductase (POR), CYP2C8, and CYP2C9, but their effect on CYP2D6 abundance was either negligible or modest (Fig. 2B and Fig. 3). CYP3A5, CYP2B6, and CYP2C19 abundance levels were below the limit of detection (and therefore not shown), likely because we used S9 fractions.

Except for UGT1A4, alcoholic or HCV cirrhosis resulted in a similar decrease $(>40 \%$ vs. control) in hepatic abundance of UGT1A4,
TABLE 3

Protein abundance of drug-metabolizing enzymes (DMEs) in human livers (picomoles per gram tissue)

\begin{tabular}{lccc}
\hline & Control & Alcoholic Cirrhotic & HCV Cirrhotic \\
\hline CYP3A4 & $309.0 \pm 240.2$ & $35.6 \pm 39.3$ & $69.9 \pm 88.6$ \\
CYP2C9 & $69.6 \pm 38.6$ & $31.5 \pm 21.0$ & $29.1 \pm 15.3$ \\
CYP2D6 & $28.2 \pm 13.6$ & $20.3 \pm 12.6$ & $18.1 \pm 9.2$ \\
CYP2E1 & $190.7 \pm 67.1$ & $50.9 \pm 39.5$ & $77.7 \pm 49.5$ \\
CYP1A2 & $72.3 \pm 53.5$ & $12.5 \pm 12.3$ & $16.2 \pm 14.5$ \\
CYP2A6 & $192.1 \pm 171.7$ & $69.5 \pm 69.5$ & $60.3 \pm 55.7$ \\
CYP2C8 & $4.6 \pm 2.8$ & $1.9 \pm 1.3$ & $2.1 \pm 1.1$ \\
POR & $95.0 \pm 40.6$ & $37.5 \pm 12.0$ & $47.9 \pm 18.9$ \\
UGT1A4 & $218 \pm 109.7$ & $18.1 \pm 21.9$ & $50.4 \pm 32.9$ \\
UGT1A6 & $34.3 \pm 42.5$ & $1.3 \pm 0.6$ & $1.7 \pm 1.1$ \\
UGT2B7 & $331.6 \pm 388.6$ & $47.4 \pm 31.4$ & $52.1 \pm 35.3$ \\
UGT2B15 & $79.7 \pm 34.7$ & $40.9 \pm 32.0$ & $36.2 \pm 22.5$ \\
CES1 & $10,724 \pm 5348$ & $2608 \pm 1735$ & $3837 \pm 1961$ \\
CES2 & $1236 \pm 451$ & $1026 \pm 410$ & $1246 \pm 677$ \\
ADH1A & $13,549 \pm 4228$ & $2794 \pm 2046$ & $7948 \pm 5778$ \\
ADH1B & $141,053 \pm 30,110$ & $32,980 \pm 32,510$ & $68,535 \pm 53,368$ \\
ADH1C & $16,607 \pm 4484$ & $4297 \pm 2967$ & $7304 \pm 5177$ \\
ALDH1A1 & $13,606 \pm 2183$ & $7743 \pm 2251$ & $8716 \pm 2290$ \\
CYP3A5 & $<$ LLOQ & $<$ LLOQ & $<$ LLOQ \\
UGT2B6 & $<$ LLOQ & $<$ LLOQ & $<$ LLOQ \\
UGT1A1 & $<$ LLOQ & $<$ LLOQ & $<$ LLOQ \\
UGT2B17 & $<$ LLOQ & $<$ LLOQ & $<$ LLOQ \\
\hline
\end{tabular}

POR, cytochrome P450 reductase; HCV, hepatitis C virus; $\mathrm{LLOQ}$, lower limit of quantification.

UGT1A6, UGT2B7, and UGT2B15 (Fig. 4); however, this decrease was greater for UGT1A4 in alcoholic versus HCV cirrhotic livers. Likewise, except for CES2, the abundance of CES1, ADH1A, ADH1B, $\mathrm{ADH} 1 \mathrm{C}$, and ALDH1A1 was decreased in alcoholic or HCV livers versus control livers; however, this decrease was greater for ADH1A and ADH1B in alcoholic versus HCV cirrhotic livers (Fig. 4). Relative abundance [i.e., peak area ratio per milligram of protein] of AOX1, FMO3, EPHX1, and EPHX2 was decreased to a similar extent in alcoholic or HCV cirrhotic livers versus control livers (Fig. 5).

PBPK Prediction of Effect of Liver Cirrhosis on Zidovudine and Morphine PK. Although the original Simcyp liver cirrhosis module poorly predicted changes in zidovudine and morphine AUC in subjects with Child Pugh C cirrhosis, integration of UGT2B7 or UGT2B7 and OCT1 protein abundance data of the cirrhotic livers into the PBPK models significantly improved the prediction of zidovudine and morphine PK profiles, respectively, in subjects with Child Pugh C cirrhosis (Figs. 6 and 7; Table 5).

\section{Discussion}

The absolute (using purified protein or peptides) or relative protein quantification methods were selected based on the availability of purified proteins and peptides. As discussed, these different methods yield equally valid measurements of differential protein abundance data between diseased and control tissue (Bhatt and Prasad, 2018). Thus, the method chosen does not, in any way, confound interpretation of the data presented here. Owing to scarring from cirrhosis and consistent with our previous data on total membrane proteins (Wang et al., 2016), we observed a significantly lower total protein content per gram of liver tissue in cirrhotic versus control livers. Thus, the protein abundance of individual DMEs presented here were normalized to the gram of total tissue weight. In control livers, except for CYP2C9, the relative order of protein abundance in our control livers was consistent with the previous published proteomics data (Ohtsuki et al., 2012; Fallon et al., 2013; Achour et al., 2014; Groer et al., 2014; Michaels and Wang, 2014). Consistent with historical data (Shimada et al., 1994), but in variance with the more recent proteomics data, the 
TABLE 4

Relative abundance of drug-metabolizing enzymes abundance in alcoholic or hepatitis C virus (HCV) cirrhotic vs. control livers (\%)

\begin{tabular}{lcc}
\hline & Alcoholic vs. Control & HCV vs. Control \\
\hline$<25 \%$ & UGT1A6 $>>$ UG/T1A4 $*$ CYP3A4 $>$ UGT2B7 $>$ & UGT1A6 $>>$ UGT2B7 $>$ CYP1A2 $>$ CYP3A4 $>$ UGT1A4 $*$ \\
& CYP1A2 $>$ AOX1 $>$ CES1 & \\
$25 \%-50 \%$ & CYP2E1 $>$ FMO3 $>$ EPHX1 $>$ CYP2A6 $>$ EPHX2 $>$ POR $>$ & AOX1 $>$ CYP2A6 $>$ CES1 $>$ FMO3 $>$ CYP2E1 $>$ EPHX1 $>$ \\
CYPC8 $>$ CYP2C9 & CYP2C9 $>$ EPHX2 $>$ UGT2B15 $>$ CYPC8 \\
$50 \%-100 \%$ & UGT2B15 $>$ CYP2D6 & POR \\
No significant difference & CES2 & CYP2D6, CES2 \\
\hline
\end{tabular}

CES, carboxylesterase; POR, cytochrome P450 reductase.

*UGT1A4 abundance was significantly lower in the alcoholic cirrhotic livers vs. HCV cirrhotic livers.

abundance of CYP3A4 was greater than that of CYP2C9. Protein abundance of the major P450 and non-CYP DMEs showed significant and enzyme-dependent decrease in alcoholic and HCV cirrhotic livers compared with control livers. In addition, some enzymes showed differences in abundance because of cirrhosis (alcohol vs. HCV).

Although the mechanisms of decreased DME abundance in liver cirrhosis or between alcoholic and HCV cirrhosis are unclear, inflammation-induced cytokines and their association with decreased DME gene expression is one potential mechanism for the reduced DME abundance (Sewer et al., 1997; Iber and Morgan, 1998; Iber et al., 1999; Hardwick et al., 2013; Bachour-El Azzi et al., 2014). The inflammatory cytokines act through nuclear factor $\kappa$-light-chain enhancer of activated $\mathrm{B}$ cells and cause transrepression of the pregnane $\mathrm{X}$ receptor, a central transcription factor regulating expression of multiple DMEs (Pascussi et al., 2001; Hardwick et al., 2013); however, more than one mechanism, including epigenetic regulation, may also be involved (Oda et al., 2014).

Our data are generally consistent with the available in vivo or in vitro data on the activity or abundance of P450s and UGTs in subjects with cirrhosis; however, most of the data in the literature do not report on the cause of cirrhosis. Using Western blotting, Guengerich and Turvy, 1(991) reported that CYP1A2, CYP2E1, and CYP3A4 abundance in cirrhotic livers ( $n=42$; cause of cirrhosis unknown) was $51 \%, 81 \%$, and $58 \%$, respectively, of the control livers $(n=36)$. In the same report, CYP2C9 abundance was greater (117\%) in cirrhotic versus control livers, which is contradicted by our data and another report using Western blotting and tolbutamide 4-hydroxylase activity (George et al., 1995). In vivo studies also show significantly lower metabolism (4\%$70 \%$ vs. control subjects) as measured by either the urinary or plasma metabolic ratio of caffeine (CYP1A2 substrate) (Frye et al., 2006), 7-hydroxycoumarin (CYP2A6 substrate) (Sotaniemi et al., 1995), mephenytoin, or omeprazole (CYP2C19 substrates) (Adedoyin et al., 1998; Ohnishi et al., 2005), debrisoquine or atomoxetine (CYP2D6 substrates), (Adedoyin et al., 1998; Chalon et al., 2003; Frye et al., 2006), chlrozoxazone (CYP2E1 substrate) (Frye et al., 2006), and cortisol (CYP3A4 substrate) (Ohnishi et al., 2005). Our data are consistent with these observations except that we observed either negligible or modest effect of liver cirrhosis on CYP2D6 abundance (Johnson et al., 2010). This difference is perhaps due to differences in
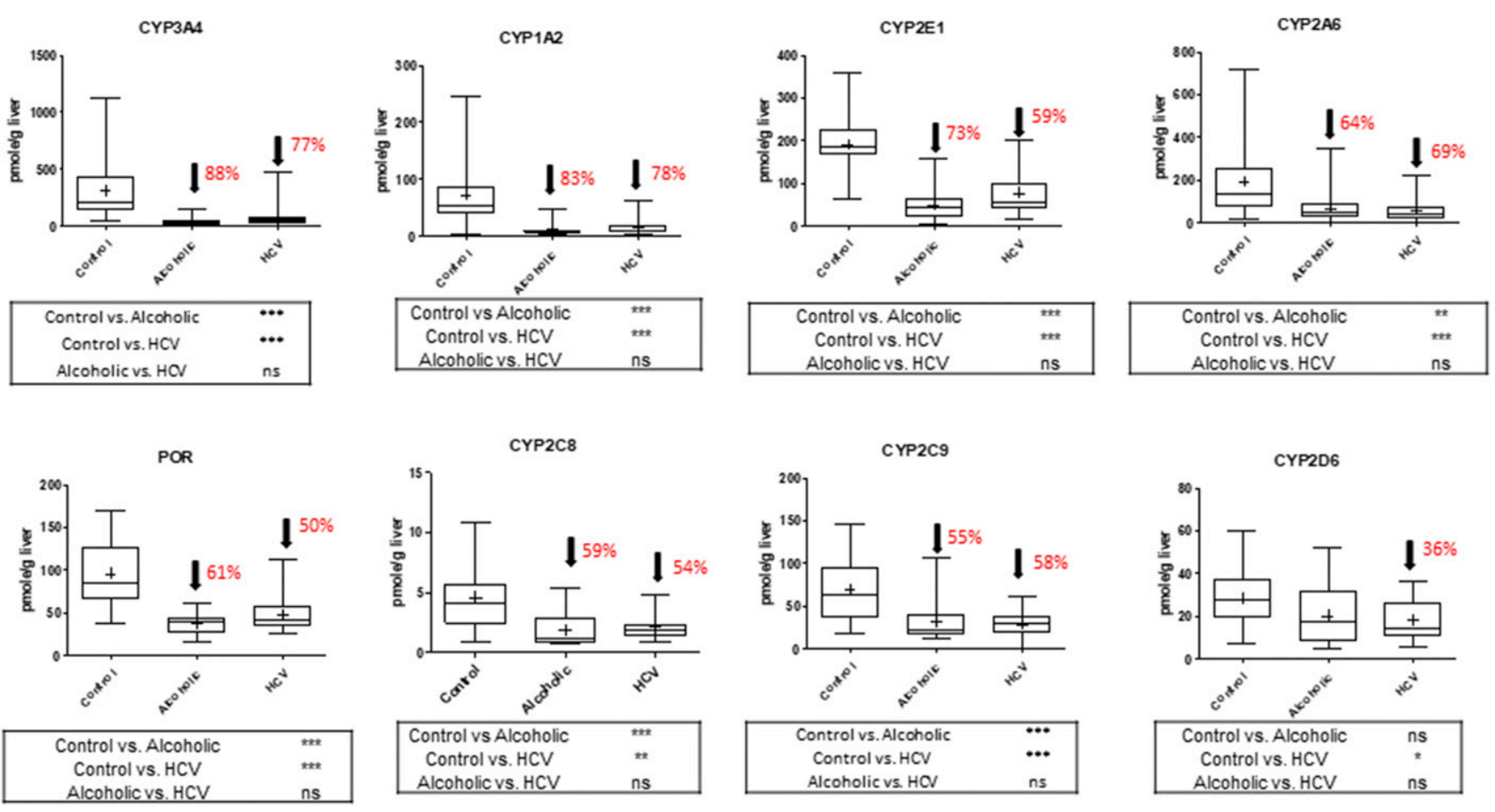

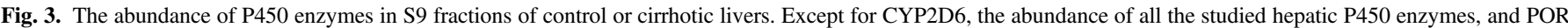

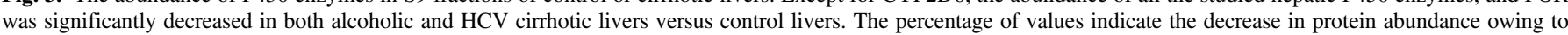

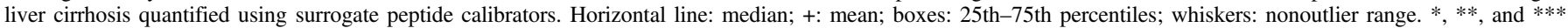
indicate $P$ values of $<0.05,<0.01$, and $<0.001$, respectively, using the Kruskal-Wallis test followed by Dunn's multiple comparison test. ns, nonsignificant. 

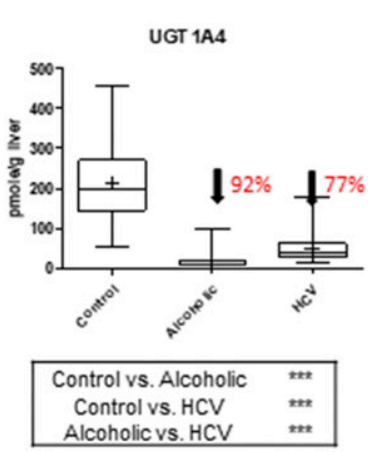

CES1
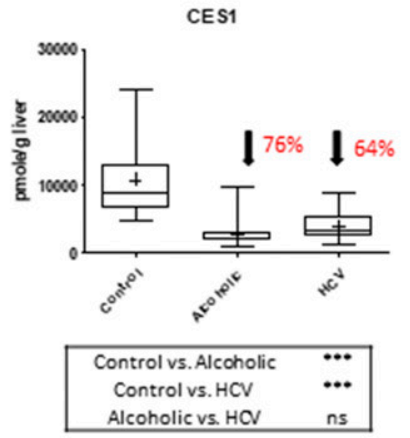

ADH1C

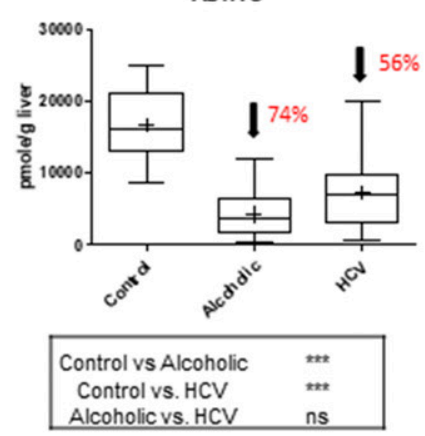

UGT1AG

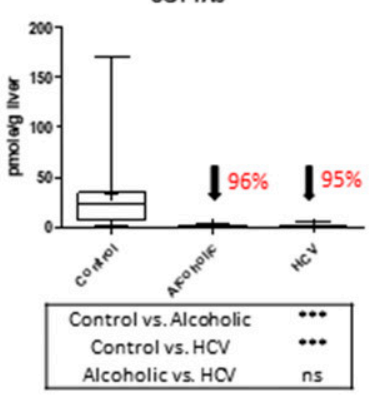

CES2

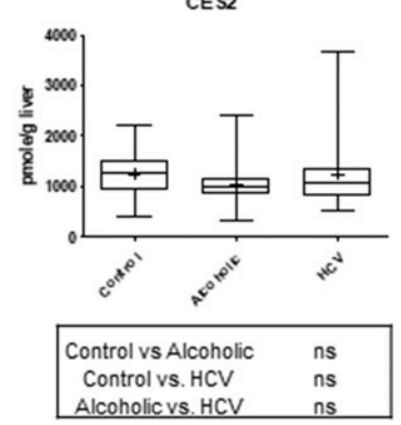

ALDH1A1

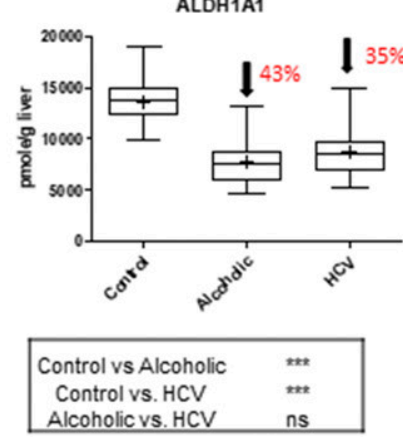

UGT2B7

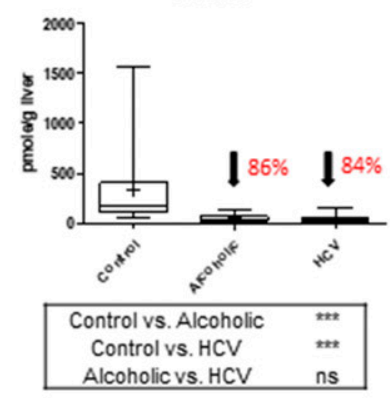

ADH1A

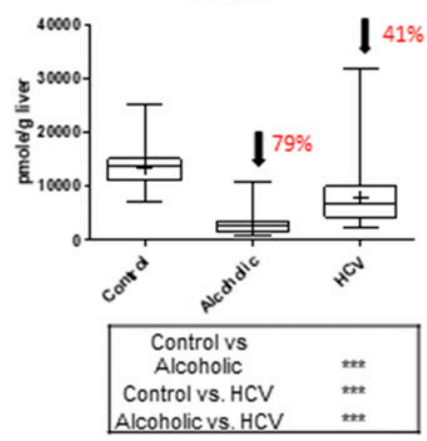

UGT 2815

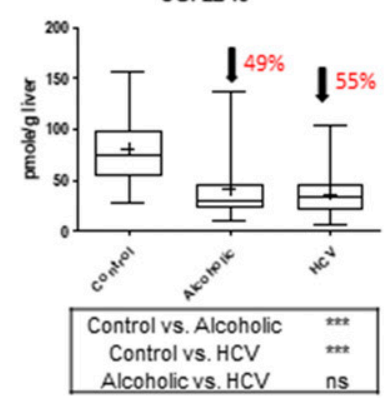

ADH1B

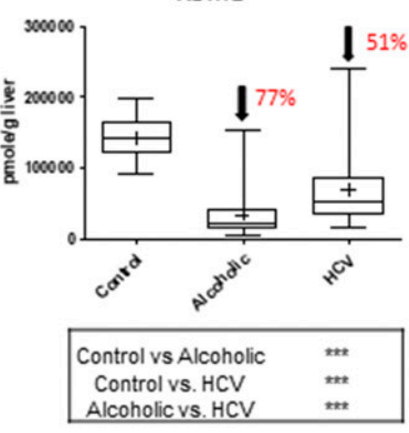

Fig. 4. The abundance of UGTs, CESs, ADHs, and ALDH1A1 enzymes in S9 fractions of control or cirrhotic livers. UGTs, CES1, ADHs, and ALDH1A1 protein abundance was decreased in cirrhotic versus control livers; however, CES2 abundance was not affected by cirrhosis. UGT1A1 abundance was detectable in only a few samples and therefore is not shown here. Except for UGT1A4, ADH1A, and ADH1B, the abundance of DMEs was not significantly different between alcoholic versus HCV livers. The percentage values indicate the magnitude of decrease in hepatic protein abundance due to liver cirrhosis. The abundance of UGTs was quantified using surrogate peptides as calibrators, whereas CESs, ADHs, and ALDH1A1 were quantified using the corresponding purified protein as a calibrator. Horizontal line: median; +: mean; boxes: 25 th-75th percentiles; whiskers: nonoutlier range. *,**, and *** indicate $P$ values of $0.05,<0.01$, and $<0.001$, respectively, using the Kruskal-Wallis test, followed by Dunn's multiple comparison test. ns, nonsignificant.

CYP2D6 SNPs between our samples and those in the preceding study. Limited data are available on the effect of cirrhosis on non-P450 enzyme activity. For example, mRNA levels of UGTs are downregulated in the liver diseases (Congiu et al., 2002). Nonalcoholic steatohepatitis affects UGT mRNA expression in human livers differentially; UGT1A9, 2B10, 3A1, UGT2A3, 2B15, and 2B28 mRNA expression is increased; however, mRNA level of UGT1A9 and 1A6 is decreased (Hardwick et al., 2013). In addition, the in vivo clearance of zidovudine and morphine (UGT2B7 substrates) is significantly decreased in patients with cirrhosis (Singlas et al., 1989; Hasselstrom et al., 1990; Taburet et al., 1990). The abundance of AOX1, FMO3, EPHX1, and EPHX2 in cirrhotic livers (vs. control livers; quantified as relative values) also revealed clear disease-dependent changes. Whereas the data in the literature are not available for changes in AOX1 and FMO3 protein abundance or in vivo activity attributable to cirrhosis, a $50 \%$ decrease in the EPHX protein abundance in cirrhotic livers versus control livers reported by Guengerich and Turvy (1991) is consistent with our data.
Interestingly, liver cirrhosis is associated with differential effect on the abundance of CES1 versus CES2. Although there is no direct evidence in the literature of differential regulation of CES2 versus CES1 in liver diseases, CES2 is thought to prevent liver steatosis (Li et al., 2016) and help reverse obesity-induced diacylglycerol accumulation (Ruby et al., 2017). As hepatic steatosis is commonly observed in alcoholic and HCV cirrhosis (Kralj et al., 2016), we speculate that a compensatory upregulation of CES2 in liver cirrhosis potentially explains our finding.

Existing PBPK models that rely on in vivo or in vitro changes in hepatic enzyme activity due to cirrhosis have several limitations. First, these studies are limited to enzymes where selective probe drugs or specific antibodies are available. Second, most of the in vivo studies are based on a relatively small number of samples or subjects and can be confounded by other factors affecting metabolite-to-parent ratio such as varying renal function and genotype (Johnson et al., 2010; Jamei, 2016). Third, the semiquantitative nature of Western blotting and lack of correlation between mRNA versus activity are limitations of the 

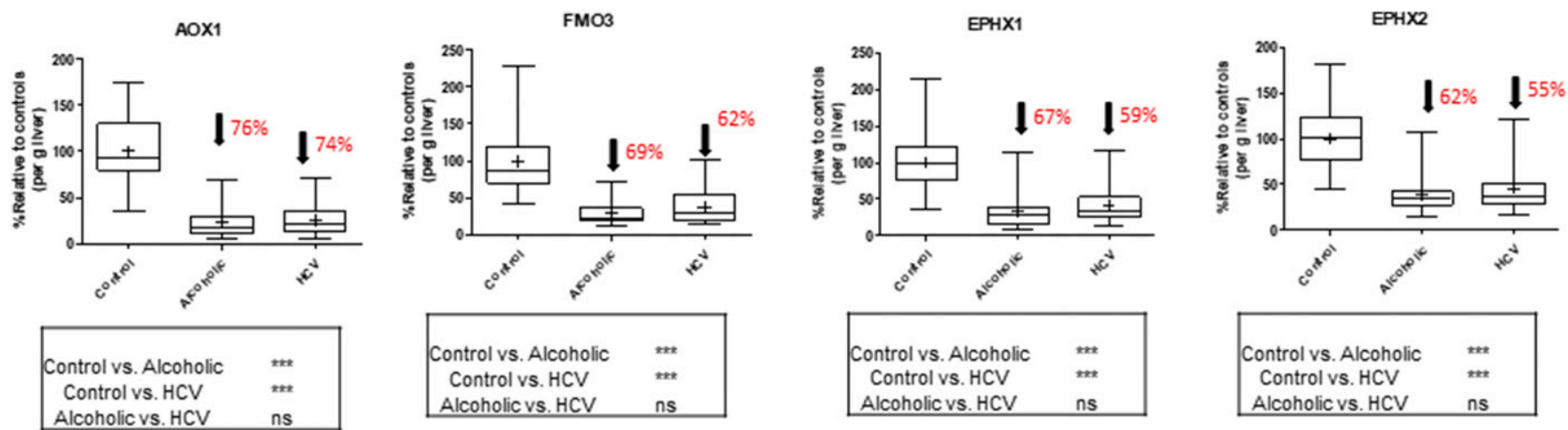

Fig. 5. Relative abundance of AOX1, FMO3, and EPHXs in S9 fractions of cirrhotic versus control livers. Hepatic abundance of AOX1, FMO3, EPHX1, and EPHX2 was significantly lower in alcoholic or HCV cirrhotic livers versus control livers. The percent values indicate the magnitude of decrease in protein abundance resulting from liver cirrhosis. Data shown are relative changes in surrogate peptide area ratios (light/heavy) normalized by per gram of liver tissue and considering control liver data as $100 \%$. Horizontal line: median; +: mean; boxes: 25th-75th percentiles; whiskers: nonoutlier range. *, **, and *** indicate $P$ value of $<0.05,<0.01$ and $<0.001$, respectively, using the Kruskal-Wallis test followed by Dunn's multiple comparison test. NS, nonsignificant.

literature data discussed here. Therefore, selective and multiplexed quantification of DMEs by quantitative proteomics could serve as an alternate method to predict liver cirrhosisassociated changes in the hepatic clearance. To illustrate the application of this approach, we integrated the UGT2B7 protein abundance data shown here into Simcyp to successfully predict pharmacokinetics of zidovudine and morphine in subjects with Child Pugh C cirrhosis. These two drugs were selected because they are known to be extensively metabolized by UGT2B7 (Coffman et al., 1997; Barbier et al., 2000). In the case, of morphine, which is an OCT1 and UGT2B7 substrate, we integrated the changes in both transporter (OCT1) (from our data in Wang et al. (2016)) and UGT enzyme abundance (UGT2B7) in our PBPK model. About $70 \%$ of morphine is eliminated as glucuronide conjugate primarily by hepatic UGT2B7, where OCT1 mediates the rate limiting uptake of morphine into the cell (Emoto et al., 2017). Since the cirrhotic livers we studied were obtained from patients with end-stage liver disease, we assumed that they were representative of patients with severe liver cirrhosis (Child

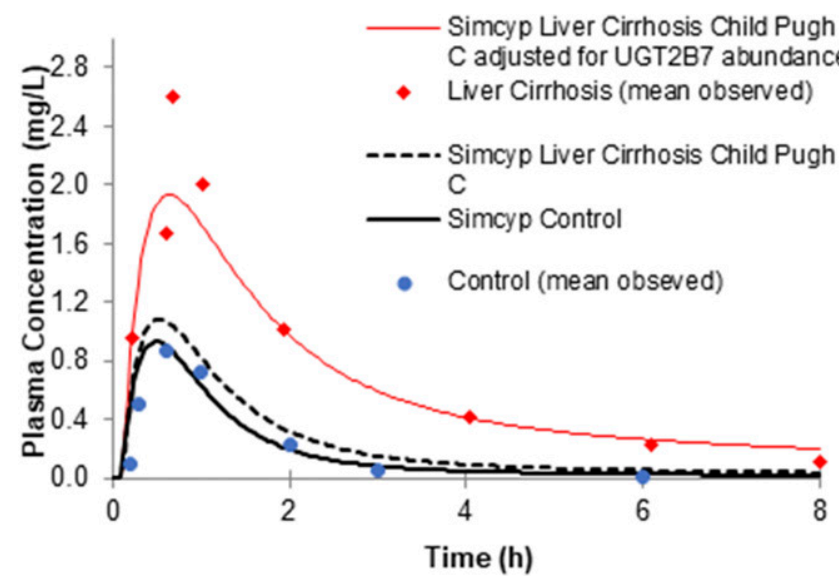

Fig. 6. Prediction of zidovudine PK in liver cirrhosis subjects using a PBPK model. Observed (data points) and predicted (lines) zidovudine PK profiles in control and Child Pugh C hepatic cirrhosis subjects. The Simcyp Child Pugh C model poorly predicted zidovudine PK in cirrhotic patients, whereas the refined Simcyp model adjusted for UGT2B7 abundance in this population significantly improved the predictions. The continuous and stippled black lines are the predicted profiles using the default Simcyp healthy subject (control) and the Child Pugh C model, respectively. The red line is the predicted profile when the Simcyp Child Pugh C model was adjusted for the decrease in UGT2B7 abundance due to liver cirrhosis. For these predictions, the protein abundance of UGT2B7 in the alcoholic and HCV livers was averaged.
Pugh score C). For both drugs, zidovudine and morphine, incorporation of UGT2B7 significantly improved the prediction of the PK profiles of the drugs when compared with the Simcyp default Child Pugh C model (Figs. 6 and 7; Table 5). The predicted/observed ratio of zidovudine and morphine AUC (or oral clearance) was closer to unity for our model versus Simcyp cirrhosis model. However, since OCT1 abundance (per milligram membrane protein) is affected by liver cirrhosis much less than UGT2B7, the data on the hepatic abundance of the latter had greater influence (PK profiles not shown) in predicting changes in morphine pharmacokinetics in liver cirrhotic patients.

There are a few limitations in our study. As indicated above, our data are based on samples from end-stage liver disease. Therefore, additional studies will need to be conducted to quantify protein abundance of DMEs and transporters in mild to moderate cirrhotic livers (representative of Child Pugh score A and B). Some of the microsomal DMEs (e.g., CYP2B6 and UGT1A1) were not detectable due to their low and variable abundance particularly in the liver cirrhotic subjects or due to low

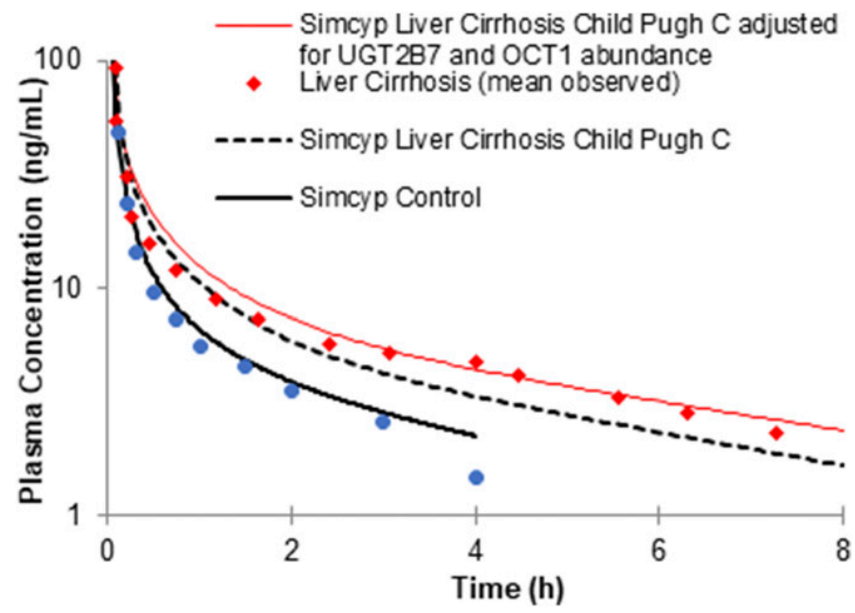

Fig. 7. Prediction of morphine PK in liver cirrhosis subjects using a PBPK model. Observed (data points) and predicted (lines) morphine PK profiles in control and hepatic cirrhosis subjects. The Simcyp Child Pugh C model poorly predicted morphine PK in cirrhotic patients, whereas the refined Simcyp model adjusted for UGT2B7 and OCT1 abundance data in this population significantly improved the predictions. The black continuous and stippled lines are predictions using the default Simcyp healthy subject (control) and the Child Pugh C model, respectively. The red line is the predicted profile when the Simcyp Child Pugh C model was adjusted for the changes in UGT2B7 and OCT1 abundance due to liver cirrhosis. For these predictions, the protein abundance of UGT2B7 in the alcoholic and HCV livers was averaged. 
TABLE 5

Predicted and observed pharmacokinetic parameters of zidovudine and morphine in healthy subjects and those with Child Pugh C cirrhosis

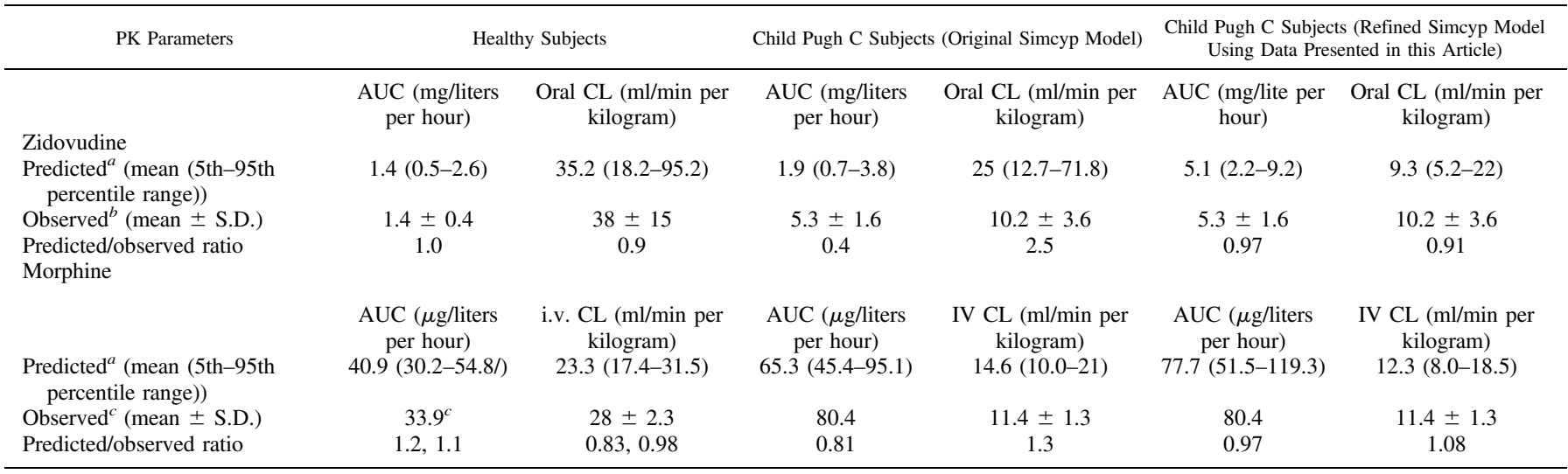

${ }^{a}$ Based on total of 100 simulations (10 virtual trials with 10 subjects). Mean, 5\%-95\% confidence intervals (CI) of the PK parameters were calculated by Non Compartment Analysis (NCA) (PK solver) of Simcyp-simulated plasma concentration-time profiles.

${ }^{b}$ Observed PK parameters (Singlas et al., 1989; Taburet et al., 1990).

${ }^{c}$ Observed PK parameters (Hasselstrom et al., 1990). Area under the curve (AUC) was calculated by NCA (PK solver) of digitized plasma concentration-time profiles.

sensitivity of the surrogate peptides; however, this could be improved by using microsomal fractions of cirrhotic livers. Despite these limitations, these data provide a proof-of-concept for the use of quantitative proteomics in quantifying the effect of liver disease on DME abundance and in predicting drug disposition in subjects with liver cirrhosis.

\section{Acknowledgments}

Prachi Jha, Department of Pharmaceutics, University of Washington, assisted with LC-MS/MS data analysis. We thank Simcyp (Certara) for the free academic license.

\section{Authorship Contributions}

Participated in research design: Prasad, Chu, Salphati, Xiao, Lee, Hop, Mathias, Lai, Liao, Humphreys, Unadkat.

Conducted experiments: Prasad, Bhatt Johnson, Chapa.

Contributed new reagents or analytic tools: Kumer.

Performed data analysis: Prasad, Bhatt, Johnson, Chapa, Unadkat.

Wrote or contributed to the writing of the manuscript: Prasad, Bhatt, Johnson,

Chapa. Chu, Salphati, Xiao, Lee, Hop, Mathias, Lai, Liao, Humphreys, Unadkat.

\section{References}

Achour B, Rostami-Hodjegan A, and Barber J (2014) Protein expression of various hepatic uridine 5 '-diphosphate glucuronosyltransferase (UGT) enzymes and their inter-correlations: a metaanalysis. Biopharm Drug Dispos 35:353-361.

Adedoyin A, Arns PA, Richards WO, Wilkinson GR, and Branch RA (1998) Selective effect of liver disease on the activities of specific metabolizing enzymes: investigation of cytochromes P450 2C19 and 2D6. Clin Pharmacol Ther 64:8-17.

Bachour-El Azzi P, Sharanek A, Abdel-Razzak Z, Antherieu S, Al-Attrache H, Savary CC, Lepage S, Morel I, Labbe G, Guguen-Guillouzo C, et al. (2014) Impact of inflammation on chlorpromazine-induced cytotoxicity and cholestatic features in HepaRG cells. Drug Metab Dispos 42:1556-1566.

Barbier O, Turgeon D, Girard C, Green MD, Tephly TR, Hum DW, and Bélanger A (2000) 3'azido-3'-deoxythimidine (AZT) is glucuronidated by human UDP-glucuronosyltransferase $2 \mathrm{~B} 7$ (UGT2B7). Drug Metab Dispos 28:497-502.

Bataller R and Brenner DA (2005) Liver fibrosis. J Clin Invest 115:209-218.

Bhatt DK and Prasad B (2018) Critical issues and optimized practices in quantification of protein abundance level to determine interindividual variability in DMET proteins by LC-MS/MS proteomics. Clin Pharmacol Ther 103:619-630.

Boberg M, Vrana M, Mehrotra A, Pearce RE, Gaedigk A, Bhatt DK, Leeder JS, and Prasad B (2017) Age-dependent absolute abundance of hepatic carboxylesterases (CES1 and CES2) by LC-MS/MS proteomics: application to PBPK modeling of oseltamivir in vivo pharmacokinetics in infants. Drug Metab Dispos 45:216-223.

Chalon SA, Desager JP, Desante KA, Frye RF, Witcher J, Long AJ, Sauer JM, Golnez JL, Smith BP, Thomasson HR, et al. (2003) Effect of hepatic impairment on the pharmacokinetics of atomoxetine and its metabolites. Clin Pharmacol Ther 73:178-191.

Coffman BL, Rios GR, King CD, and Tephly TR (1997) Human UGT2B7 catalyzes morphine glucuronidation. Drug Metab Dispos 25:1-4.

Congiu M, Mashford ML, Slavin JL, and Desmond PV (2002) UDP glucuronosyltransferase mRNA levels in human liver disease. Drug Metab Dispos 30:129-134.
Davis GL, Alter MJ, El-Serag H, Poynard T, and Jennings LW (2010) Aging of hepatitis C virus (HCV)-infected persons in the United States: a multiple cohort model of $\mathrm{HCV}$ prevalence and disease progression. Gastroenterology 138:513-521, 521e1-6.

Drozdzik M, Gröer C, Penski J, Lapczuk J, Ostrowski M, Lai Y, Prasad B, Unadkat JD, Siegmund W, and Oswald S (2014) Protein abundance of clinically relevant multidrug transporters along the entire length of the human intestine. Mol Pharm 11:3547-3555.

Emoto C, Fukuda T, Johnson TN, Neuhoff S, Sadhasivam S, and Vinks AA (2017) Characterization of contributing factors to variability in morphine clearance through PBPK modeling implemented with OCT1 transporter. CPT Pharmacometrics Syst Pharmacol 6:110-119.

Fallon JK, Neubert H, Hyland R, Goosen TC, and Smith PC (2013) Targeted quantitative proteomics for the analysis of 14 UGT1As and -2Bs in human liver using NanoUPLC-MS/MS with selected reaction monitoring. J Proteome Res 12:4402-4413.

Frye RF, Zgheib NK, Matzke GR, Chaves-Gnecco D, Rabinovitz M, Shaikh OS, and Branch RA (2006) Liver disease selectively modulates cytochrome P450-mediated metabolism. Clin Pharmacol Ther 80:235-245.

George J, Murray M, Byth K, and Farrell GC (1995) Differential alterations of cytochrome P450 proteins in livers from patients with severe chronic liver disease. Hepatology 21:120-128.

Gröer C, Busch D, Patrzyk M, Beyer K, Busemann A, Heidecke CD, Drozdzik M, Siegmund W, and Oswald S (2014) Absolute protein quantification of clinically relevant cytochrome P450 enzymes and UDP-glucuronosyltransferases by mass spectrometry-based targeted proteomics. $J$ Pharm Biomed Anal 100:393-401.

Guengerich FP and Turvy CG (1991) Comparison of levels of several human microsomal cytochrome P-450 enzymes and epoxide hydrolase in normal and disease states using immunochemical analysis of surgical liver samples. J Pharmacol Exp Ther 256:1189-1194.

Hardwick RN, Ferreira DW, More VR, Lake AD, Lu Z, Manautou JE, Slitt AL, and Cherrington NJ (2013) Altered UDP-glucuronosyltransferase and sulfotransferase expression and function during progressive stages of human nonalcoholic fatty liver disease. Drug Metab Dispos 41: during prog 561 .

Hasselström J, Eriksson S, Persson A, Rane A, Svensson JO, and Säwe J (1990) The metabolism and bioavailability of morphine in patients with severe liver cirrhosis. Br J Clin Pharmacol 29:289-297.

Iber H and Morgan ET (1998) Regulation of hepatic cytochrome P450 2C11 by transforming growth factor-beta, hepatocyte growth factor, and interleukin-11. Drug Metab Dispos 26: $1042-1044$.

Iber H, Sewer MB, Barclay TB, Mitchell SR, Li T, and Morgan ET (1999) Modulation of drug metabolism in infectious and inflammatory diseases. Drug Metab Rev 31:29-41.

Jamei M (2016) Recent advances in development and application of physiologically-based pharmacokinetic (PBPK) models: a transition from academic curiosity to regulatory acceptance. Curr Pharmacol Rep 2:161-169.

Johnson TN, Boussery K, Rowland-Yeo K, Tucker GT, and Rostami-Hodjegan A (2010) A semimechanistic model to predict the effects of liver cirrhosis on drug clearance. Clin Pharmacokinet 49:189-206.

Kralj D, Virović Jukić L, Stojsavljević S, Duvnjak M, Smolić M, and Čurčić IB (2016) Hepatitis C virus, insulin resistance, and steatosis. J Clin Transl Hepatol 4:66-75.

Li Y, Zalzala M, Jadhav K, Xu Y, Kasumov T, Yin L, and Zhang Y (2016) Carboxylesterase 2 prevents liver steatosis by modulating lipolysis, endoplasmic reticulum stress, and lipogenesis and is regulated by hepatocyte nuclear factor 4 alpha in mice. Hepatology 63:1860-1874.

Michaels S and Wang MZ (2014) The revised human liver cytochrome P450 "Pie": absolute protein quantification of CYP4F and CYP3A enzymes using targeted quantitative proteomics. Drug Metab Dispos 42:1241-1251.

Oda S, Fukami T, Yokoi T, and Nakajima M (2014) Epigenetic regulation of the tissue-specific expression of human UDP-glucuronosyltransferase (UGT) 1A10. Biochem Pharmacol 87: 660-667.

Ohnishi A, Murakami S, Akizuki S, Mochizuki J, Echizen H, and Takagi I (2005) In vivo metabolic activity of CYP2C19 and CYP3A in relation to CYP2C19 genetic polymorphism in chronic liver disease. J Clin Pharmacol 45:1221-1229.

Ohtsuki S, Schaefer O, Kawakami H, Inoue T, Liehner S, Saito A, Ishiguro N, Kishimoto W, Ludwig-Schwellinger E, Ebner T, et al. (2012) Simultaneous absolute protein quantification of transporters, cytochromes P450, and UDP-glucuronosyltransferases as a novel approach for the characterization of individual human liver: comparison with mRNA levels and activities. Drug Metab Dispos 40:83-92. 
Pascussi JM, Drocourt L, Gerbal-Chaloin S, Fabre JM, Maurel P, and Vilarem MJ (2001) Dual effect of dexamethasone on CYP3A4 gene expression in human hepatocytes. Sequential role of glucocorticoid receptor and pregnane X receptor. Eur J Biochem 268: 6346-6358

Prasad B, Evers R, Gupta A, Hop CE, Salphati L, Shukla S, Ambudkar SV, and Unadkat JD (2014) Interindividual variability in hepatic organic anion-transporting polypeptides and P-glycoprotein (ABCB1) protein expression: quantification by liquid chromatography tandem mass spectroscopy and influence of genotype, age, and sex. Drug Metab Dispos 42:78-88.

Rasool MF, Khalil F, and Läer S (2017) Optimizing the clinical use of carvedilol in liver cirrhosis using a physiologically based pharmacokinetic modeling approach. Eur J Drug Metab Pharmacokinet 42:383-396.

Rodgers T, Leahy D, and Rowland M (2005) Physiologically based pharmacokinetic modeling 1 : predicting the tissue distribution of moderate-to-strong bases. J Pharm Sci 94:1259-1276.

Ruby MA, Massart J, Hunerdosse DM, Schönke M, Correia JC, Louie SM, Ruas JL, Näslund E, Nomura DK, and Zierath JR (2017) Human carboxylesterase 2 reverses obesity-induced diacylglycerol accumulation and glucose intolerance. Cell Reports 18:636-646.

Scaglione S, Kliethermes S, Cao G, Shoham D, Durazo R, Luke A, and Volk ML (2015) The epidemiology of cirrhosis in the United States: a population-based study. J Clin Gastroentero 49:690-696.

Sewer MB, Koop DR, and Morgan ET (1997) Differential inductive and suppressive effects of endotoxin and particulate irritants on hepatic and renal cytochrome P-450 expression. J Pharmacol Exp Ther 280:1445-1454.

Shi J, Wang X, Nguyen J, Wu AH, Bleske BE, and Zhu HJ (2016) Sacubitril is selectively activated by carboxylesterase 1 (CES1) in the liver and the activation is affected by CES1 genetic variation. Drug Metab Dispos 44:554-559.

Shimada T, Yamazaki H, Mimura M, Inui Y, and Guengerich FP (1994) Interindividual variations in human liver cytochrome P-450 enzymes involved in the oxidation of drugs, carcinogens and toxic chemicals: studies with liver microsomes of 30 Japanese and 30 Caucasians. J Pharmaco Exp Ther 270:414-423.
Singlas E, Pioger JC, Taburet AM, Colaneri S, and Fillastre JP (1989) Comparative pharmacokinetics of zidovudine (AZT) and its metabolite (G.AZT) in healthy subjects and HIV seropositive patients. Eur J Clin Pharmacol 36:639-640.

Sotaniemi EA, Rautio A, Bäckstrom M, Arvela P, and Pelkonen O (1995) CYP3A4 and CYP2A6 activities marked by the metabolism of lignocaine and coumarin in patients with liver and kidney diseases and epileptic patients. Br J Clin Pharmacol 39:71-76.

Stagg MP, Cretton EM, Kidd L, Diasio RB, and Sommadossi JP (1992) Clinical pharmacokinetics of $3^{\prime}$-azido-3'-deoxythymidine (zidovudine) and catabolites with formation of a toxic catabolite, 3'-amino-3'-deoxythymidine. Clin Pharmacol Ther 51:668-676.

Taburet AM, Naveau S, Zorza G, Colin JN, Delfraissy JF, Chaput JC, and Singlas E (1990) Pharmacokinetics of zidovudine in patients with liver cirrhosis. Clin Pharmacol Ther 47:731-739.

Wang L, Collins C, Kelly EJ, Chu X, Ray AS, Salphati L, Xiao G, Lee C, Lai Y, Liao M, et al. (2016) Transporter expression in liver tissue from subjects with alcoholic or hepatitis $\mathrm{C}$ cirrhosis quantified by targeted quantitative proteomics. Drug Metab Dispos 44:1752-1758.

Woodhouse KW, Mitchison HC, Mutch E, Wright PD, Rawlins MD, and James OF (1985) The metabolism of 7-ethoxycoumarin in human liver microsomes and the effect of primary biliary cirrhosis: implications for studies of drug metabolism in liver disease. Br J Clin Pharmacol 20:77-80

Zhang Z and Unadkat JD (2017a) Development of a novel maternal-fetal physiologically based pharmacokinetic model II: verification of the model for passive placental permeability drugs. Drug Metab Dispos 45:939-946.

Zhang Z and Unadkat JD (2017b) Verification of a maternal-fetal physiologically based pharmacokinetic model for passive placental permeability drugs. Drug Metab Dispos 45:939-946.

Address correspondence to: Jashvant D. Unadkat, Department of Pharmaceutics, University of Washington, Seattle, P.O. Box 357610, WA 98195. E-mail: jash@u.washington.edu 